\title{
Enric Lluch i Martín (1928-2012). In memoriam. Una mirada des del Departament de Geografia i Documents d'Anàlisi Geogràfica
}

\author{
Maria Dolors Garcia Ramon \\ Universitat Autònoma de Barcelona. Departament de Geografia \\ mariadolors.garcia.ramon@uab.cat
}

Recepció: febrer de 2013

Acceptació: abril de 2013

El dia 4 de desembre de 2012, l'Enric Lluch va morir a Barcelona als 84 anys. Sabíem que la seva salut era molt fràgil, però la notícia va colpir fortament el professorat del nostre Departament de Geografia, que ell havia fundat en un ja llunyà setembre de 1969. L'Enric també va fundar i inspirar la present publicació periòdica - DOCUMENTS D'ANÀLISI GEOGRÀFICA—, que ha estat tota una referència en la renovació de la geografia catalana dels últims trenta anys. Al final d'aquest escrit, m'hi referiré, sobretot als primers temps, quan el paper de l'Enric va ser certament decisiu.

L'Enric Lluch havia nascut l'any 1928 a Barcelona, però va créixer a Vilassar de Mar, poble del qual conservava un gran record. Es va llicenciar en Història a la Universitat de Barcelona i va seguir també els mig clandestins Estudis Universitaris Catalans. A finals de la dècada de 1950, i després d'una breu estada a Irlanda, va anar a la Universitat de Liverpool com a lector i allà va conèixer els nous enfocaments que s'obrien camí en la geografia internacional. Més tard, es va incorporar a la Universitat de Barcelona, però l'any 1966 en va ser expulsat. L'Enric Lluch, que havia estat present en l'acte de la constitució del Sindicat Democràtic d'Estudiants (l'anomenada "Caputxinada»), va ser després un dels signants del telegrama que denunciava l'entrada violenta de la policia en el recinte universitari, telegrama que va motivar l'expedient $\mathrm{i}$ l'expulsió posterior de destacats professors del moment.

El 1969 va tenir l'oportunitat de tornar a la universitat per incorporar-se a la Facultat de Lletres de la tot just creada Universitat Autònoma de Barcelona (aleshores a Sant Cugat), on va fundar el que seria, a la llarga, l'actual Departament de Geografia (inicialment, un component de la Divisió de 
Ciències Socials) i allà va ensenyar durant més de trenta anys. Cal remarcar que l'Enric Lluch no concebia la geografia sense una gran vinculació amb la societat, i per això, al llarg de la seva vida, va participar en innombrables iniciatives cíviques (Congrés de Cultura Catalana, Rosa Sensat, Societat Catalana de Geografia i Societat Catalana d'Ordenació del Territori, per citar-ne només algunes).

És ben clar que l'Enric Lluch va ser una figura imprescindible en la renovació de la geografia a Catalunya a partir de la dècada de 1960, però per a aquells que hem tingut el privilegi de treballar amb ell durant molts anys ell ha significat molt més que això. Ens ha marcat profundament en la nostra manera d'entendre la geografia i de fer-ne, en el sentit que escrivia el meu company Abel Albet sobre la que ell va anomenar "escola Lluch». Es tracta d'una escola «que no és mesurable en termes de tesis, de publicacions, de deixebles, ans més aviat en una manera de fer i entendre la geografia (una geografia capaç de mantenir una actitud políticament transformadora, socialment progressista, econòmicament justa, culturalment tolerant, èticament compromesa, estèticament precisa, científicament oberta), i també en una manera de ser (caracteritzada per l'honestedat, la integritat, el rigor) traslladada, també, a la recerca i la docència en geografia» (Albet, 2007: 14).

Personalment, feia molt de temps que coneixia l'Enric. Vaig col-laborar amb ell des de l'any 1969, quan el Dr. Udina i Martorell (aleshores degà de la Facultat de Lletres de la UAB) li va proposar que organitzés els estudis de geografia en aquella universitat que aleshores s'estrenava. Però jo havia conegut l'Enric uns quants anys abans, durant el curs 1964-1965, com a alumna de l'assignatura de Geografia d'Espanya que impartia a la Universitat de Barcelona. Aquesta assignatura va ser, amb diferència, la del nivell acadèmic més elevat de tota la carrera, tant pel contingut com pels nous plantejaments $\mathrm{i}$ perspectives que hi va introduir. I em consta que la majoria dels meus companys i companyes de curs (entre els quals hi havia la Rosa Ascon i la Pilar Riera d'aquest mateix departament) dirien exactament el mateix. De fet, va ser la seva excel-lent tasca docent la que va despertar en mi la vocació geogràfica $\mathrm{i}$ em va animar a seguir estudis de postgrau d'aquesta disciplina a la Universitat de California, a Berkeley. En tornar a Barcelona, l'any 1969, vaig entrar com a ajudant seva a la Facultat de Lletres, a Sant Cugat (al cap de poc temps, ho van fer la Laura Zumín i l'Helena Estalella). He tingut, doncs, el privilegi de conèixer durant molts anys la magnitud de la tasca docent, intel.lectual i acadèmica de l'Enric Lluch, que crec que sovint no ha estat prou coneguda ni reconeguda.

L'Enric Lluch va aportar, als ensenyaments de geografia de la UAB, una visió molt innovadora de la disciplina, un fet que penso que està molt lligat a les seves estades a les universitats angleses i irlandeses durant la dècada de 1950, uns anys en què la geografia internacional —en particular l'anglosaxonacomençava a marcar les pautes de la disciplina de forma molt ràpida $\mathrm{i}$ contundent. L'Enric Lluch va tenir un paper clau en la introducció a casa nostra dels enfocaments anglosaxons i, a més, els va saber integrar amb l'important llegat 
històric de la geografia catalana, procedent dels anys 1930, quan l'escola regional francesa hi tenia molt de pes. També havia estat l'introductor al nostre país de moltes de les aportacions dels urbanistes, economistes i geògrafs italians dels anys seixanta i setanta. Totes aquestes idees es van materialitzar en la manera d'entendre la disciplina al Departament de la UAB des de principis de la dècada de 1970. Els ensenyaments de geografia a la Divisió de Ciències Socials de la tot just creada Facultat de Lletres de la UAB eren certament atraients. La concepció mateixa d'aquesta divisió era imaginativa: l'ambient, a l'Autònoma, era ben especial en aquells primers anys de la seva existència. Semblava que era possible ignorar els motlles de la normativa ministerial... Semblava que qualsevol bona idea es podia dur a la pràctica, $\mathrm{i}$ en bona mesura era així. A la llarga, no ho seria ben bé, però aquell ambient estimulava l'esperit innovador en una disciplina encara poc institucionalitzada com era la geografia a casa nostra i l'Enric ho va saber fer molt bé. Cal dir que, de bon començament, la docència era absolutament prioritària, molt en la línia del que sempre ha pensat l'Enric Lluch, i també era una preocupació dominant entre els que van posar en marxa aquella Facultat de Lletres.

L'Enric Lluch va deixar una forta empremta en el professorat que es va anar incorporant al Departament, així com en les diferents promocions de llicenciats i llicenciades que el van tenir com a docent, fins que es va jubilar l'any 1994. Podríem dir que va exercir el seu mestratge de forma estrictament acadèmica, però també socràtica, és a dir, de forma individualitzada i proporcionant sempre nombrosos suggeriments i idees a qui li demanava, amb una generositat molt infreqüent.

L'Enric Lluch va esdevenir un punt de referència pel seu rigor científic, però també per la seva actitud ètica i cívica, que es reflectia també en la seva vida acadèmica. Va treballar incansablement $i$ en diferents instàncies per aconseguir crear una universitat democràtica i per fer-ne possible la governabilitat. Recordem que l'Enric va ser un dels impulsors i redactors del famós Manifest de Bellaterra de l'any 1975.

L'Enric Lluch es va caracteritzar per ser defensor i introductor de la geografia entesa com a ciència social i com a saber interdisciplinari. Segons la meva opinió, un exemple excel-lent d'això l'ofereix la Geografía de la Sociedad Humana (1982-1984) que ell va dirigir i en la qual van participar especialistes de diverses disciplines. En aquesta obra, Lluch hi presenta una renovació dels plantejaments de la geografia regional més enllà de l'escala comarcal, la més coneguda a casa nostra. La divisió regional del món que proposa supera els esquemes tradicionals (per països o continents), que eren simplistes $\mathrm{i}$ acrítics, amb poc contingut interpretatiu. És ben cert que els canvis que se simbolitzaven en la caiguda del mur del Berlín, l’any 1989, van fer envellir, de sobte, el marc analític triat, però no la concepció que hi havia al darrere $\mathrm{i}$ que encara se sosté $\mathrm{i}$ és aplicable. Aquesta perspectiva oberta $\mathrm{i}$ interdisciplinària va marcar també el nostre Departament de Geografia. Ja de bon principi, el Pla d'Estudis de Geografia de la UAB de mitjan anys setanta així ho reflectia. Era un pla d'estudis molt innovador i que probablement s'inspirava en plan- 
tejaments existents en universitats del món anglòfon. I era pioner en aquells moments pels seus continguts, ja que hi havia assignatures molt variades: des de l'economia o l'estadística (tota una revolució en la geografia catalana i espanyola del moment), fins a les geografies regionals més tradicionals (que es plantejaven a partir de la concepció de l'espai com a producte social). Però també era innovador per la seva gran flexibilitat; per exemple: a segon cicle no hi havia assignatures, sinó sis àrees o matèries on les assignatures programades variaven segons les necessitats i les disponibilitats de cada moment. Per a molts de nosaltres, els plans d'estudis posteriors (força rígids i molt més encotillats per la normativa centralista) van representar tot un retrocés, no només pels continguts, sinó també per la manca de flexibilitat.

Com ja he explicat més amunt, l'Enric va concebre els estudis de geografia com els d'una ciència social i crítica. Per tant, la publicació d'una revista científica era un instrument molt potent per donar a conèixer aquesta concepció de la disciplina. Així va ser com va sorgir la idea de crear una revista de geografia des de la UAB, DOCUMENTS D’ANÀlISI GEOGRÀFICA (DAG), els inicis de la qual se situen a l'any 1974 (quan s'havia creat, "per decret de Madrid", la llicenciatura de Geografia a tots els departaments on anteriorment hi havia ensenyaments de geografia). L'Enric creia fermament que la publicació serviria per projectar, a Catalunya, a Espanya i més enllà, la manera d'entendre la geografia que teníem a la UAB. Obtenir finançament no va ser cosa facil en aquells moments, però, gràcies a la tossuderia de l'Enric, això es va resoldre, de manera que els esforços fets al llarg de l'any 1973 van culminar en la publicació d'un primer número al mes de gener de 1974. Cal dir que, en aquell primer moment, no es tractava d'una revista regular i periòdica, sinó que la idea era que fos un working paper.

Des de l'any 1974 fins al 1981, es van anar publicant tres sèries del que hem anomenat posteriorment «Pre-DAG»: els Documents d'Anàlisi Urbana (3 números: gener de 1974, desembre de 1974 i desembre de 1975), els Documents d’Anàlisi Metodològica en Geografia (2 números: desembre de 1977 i febrer de 1981) i els Documents d'Anàlisi Territorial (2 números: juliol de 1975 i juliol de 1976). Malgrat que l'Enric Lluch era al darrere de totes les publicacions, en la sèrie d'urbana també hi va tenir un paper significatiu la Laura Zumín i sobretot en Jordi Borja, que acabava de tornar de Xile i tenia molts contactes amb estudiosos de l'Amèrica Llatina. En la sèrie metodològica — també inspirada per Lluch — van ser-hi actius Maria Dolors Garcia i Antoni Tulla. Cal dir que la sèrie urbana i la metodològica tenien un enfocament molt crític, cosa que va provocar que se'n parlés força a la geografia espanyola del moment. La sèrie territorial tenia unes connotacions més tècniques, fruit dels contactes amb la geografia teoreticoquantitativa que en aquells moments ja coneixíem i també practicàvem a la UAB. Cal dir que, a principis de la dècada de 1980, es van publicar dos documents importants que Lluch també va impulsar: Una aplicació del Programa M.A.P a Catalunya (1983), editat per Pau Alegre, i La nova divisió territorial de Catalunya (1983), editat per Pilar Riera. 
A partir de 1982, i encoratjats per l'Enric Lluch i pel José Manuel Blecua (director en aquell moment del Servei de Publicacions), es va iniciar una nova etapa en les publicacions del Departament. La revista DOCUMENTS D'ANÀLISI GEOGRÀFICA naixia amb una periodicitat bianual $i$, a diferència de les sèries anteriors, els números no serien habitualment de caràcter monogràfic, a més, llur contingut es presentaria en una secció d'articles de fons i en una altra de notes i documentació. Com que l'Enric no volia (o no li agradava) ser el protagonista de gaires coses, em va proposar a mi que en fos directora i cap de redacció, proposta que vaig acceptar perquè sabia que ell seria darrere del projecte. El consell de redacció estava format per l'Enric, el Jordi Borja, el Joan Sabí, l'Antoni Tulla i jo mateixa. Més tard, hi van entrar en Joan Nogué (UdG), la Maria Villanueva, la Pilar Riera i altres. L'Enric no era a primera fila de la publicació, però sentíem que teníem tot el seu suport i que ens encoratjava. A més, participava molt activament, amb tot tipus d'idees i suggeriments, en les nombroses reunions que celebràvem. Curiosament, a l'Enric se li ha atribuït el qualificatiu de "geògraf àgraf» (Albet, 2007: 14), però, en canvi, tenia un gran interès per les publicacions i sempre va donar una gran importància al món editorial (cal no oblidar el seu paper crucial en la publicació de diverses obres molt noves de geografia a l'editorial OikosTau, de Vilassar de Mar).

Seguint els seus consells, el contingut de la revista DocumenTs era molt obert, tant des de la perspectiva interdisciplinària (història, arquitectura, etc.), com de l'origen de l'autoria. Així, es va intentar que no fos només el mirall d'allò que feiem al nostre departament (com era costum en moltes de les revistes espanyoles), sinó que s'hi van publicar també articles provinents de diferents universitats catalanes, espanyoles i nord-americanes. A més, cal recordar que, a la secció de notes i documentació, hi van aparèixer ressenyes de congressos celebrats a Anglaterra i França, ja que volíem que la revista fos, per a la geografia catalana i espanyola, com una mena de finestra cap a la resta del món.

La temàtica dels primers números va ser sobretot de geografia humana $i$, en general, el contingut dels articles era francament innovador en els àmbits català i espanyol. Entre altres exemples, trobem el que tractava del model de Hägerstrand, el de la geografia humanista o alguns articles sobre la geografia del gènere. El biaix cap a la geografia humana era evident $\mathrm{i}$ jo diria que volgut. De fet, el mateix Enric ens deia aleshores que la geografia física ja es feia a tots els altres departaments de geografia d'Espanya i que, per tant, el que calia era especialitzar-se en la temàtica humana crítica. En aquest sentit, la revista constituïa una eina important per canviar l'estil de la matèria d'estudi imperant $\mathrm{i}$ tots i totes estàvem molt satisfets del tipus de geografia que s'identificava amb la UAB. Amb la perspectiva que dóna el temps, podríem dir que la revista ha esdevingut un actiu molt important per al Departament, al qual ha donat prestigi. Efectivament, durant un bon nombre d'anys, el Departament es va donar a conèixer a través de la revista DAG, i no només a tota la península Ibèrica, sinó també a països de 
l'Amèrica Llatina. Finalment, cal dir que la revista DAG — a càrrec d'editors i editores molt més joves- continua amb molta energia i actualment ja és a punt de publicar-se'n el número 60! Però alguns de nosaltres sabem molt bé que aquesta publicació probablement no existiria sense les idees, l'empenta ni l'entossudiment de l'Enric.

\section{Referències bibliogràfiques}

LluCH, Enric (dir.) (1982-1984). Geografía de la Sociedad Humana (8 vol.). Barcelona: Planeta.

Alegre, Pau (ed.) (1983). Una Aplicació del programa M.A.P. a Catalunya. Barcelona: Universitat Autònoma de Barcelona. Departament de Geografía / Generalitat de Catalunya. Direcció General de Política Territorial.

RierA, Pilar (ed.) (1983). La nova divisió territorial de Catalunya. Bellaterra: Universitat Autònoma de Barcelona. Departament de Geografia.

Albet, Abel (2007) (ed.). Enric Lluch i Martín: l'obra escrita. Barcelona: Societat Catalana de Geografia i Institut d'Estudis Catalans. Es tracta d'una recopilació excel-lent i molt laboriosa de tots els escrits de l'Enric Lluch (alguns dels quals són molt difícils de trobar), que estan molt ben contextualitzats per l'autor. 